\title{
Soil-Transmitted Helminths, Poverty, and Malnutrition in Honduran Children Living in Remote Rural Communities
}

\section{Ana Lourdes Sanchez $z^{1,2}$, José Antonio Gabrie1, Maritza Canales³, María Mercedes Rueda ${ }^{3}$, Gustavo A. Fontecha' ${ }^{2,3}$, Patrick W. Mason ${ }^{4}$, Gonzalo Bearman ${ }^{5}$ and Michael P. Stevens ${ }^{5}$}

${ }^{1}$ Department of Health Sciences, Brock University, St. Catharines, ON, Canada. ${ }^{2}$ Microbiology Research Institute, National Autonomous University of Honduras (UNAH), Tegucigalpa, Honduras. ${ }^{3}$ School of Microbiology, National Autonomous University of Honduras (UNAH), Tegucigalpa, Honduras. ${ }^{4}$ Golden Phoenix Foundation—Quest Diagnostics Nichols Institute, Chantilly, VA, USA. ${ }^{5}$ Division of Infectious Diseases, Virginia Commonwealth University (VCU), Richmond, VA, USA.

\begin{abstract}
Soil-transmitted helminth (STH) infections are endemic in Honduras, but their prevalence according to the levels of poverty in the population has not been examined. The present cross-sectional study is aimed to determine the role of different levels of poverty in STH prevalence and infection intensity as well as the potential associations of STH infections with malnutrition and anemia. Research participants were children attending a medical brigade serving remote communities in Northern Honduras in June 2014. Demographic data were obtained, and poverty levels were determined using the unsatisfied basic needs method. STH infections were investigated by the Kato-Katz method; hemoglobin concentrations were determined with the HemoCue system; and stunting, thinness, and underweight were determined by anthropometry. Data were analyzed using descriptive statistics and univariate and multivariable logistic regression models. Among 130 children who participated in this study, a high prevalence (69.2\%) of parasitism was found and the poorest children were significantly more infected than those living in less poor communities (79.6\% vs. $61.8 \% ; P=0.030)$. Prevalence rates of Trichuris trichiura, Ascaris lumbricoides, and hookworms were $69.2 \%, 12.3 \%$, and $3.85 \%$, respectively. In total, $69 \%$ of children had anemia and $30 \%$ were stunted. Households' earthen floor and lack of latrines were associated with infection. Greater efforts should be made to reduce STH prevalence and improve overall childhood health, in particular, among the poorest children lacking the basic necessities of life.
\end{abstract}

KEYWORDS: soil-transmitted helminths, intestinal parasites, poverty, nutrition, anemia, Honduras

CITATION: Sanchez et al. Soil-Transmitted Helminths, Poverty, and Malnutrition in Honduran Children Living in Remote Rural Communities. Human Parasitic Diseases 2016:8 27-35 doi:10.4137/HPD.S33458.

TYPE: Original Research

RECEIVED: August 20, 2015. RESUBMITTED: February 11, 2016. ACCEPTED FOR PUBLICATION: February 14, 2016.

ACADEMIC EDITOR: Ashley Croft, Editor in Chief

PEER REVIEW: One peer reviewer contributed to the peer review report. Reviewers' reports totaled 79 words, excluding any confidential comments to the academic editor.

FUNDING: This study was conducted with the Brock University internal research funding received by ALS. The authors confirm that the funder had no influence over the study design, content of the article, or selection of this journal.

COMPETING INTERESTS: Authors disclose no potential conflicts of interest.
COPYRIGHT: ๑ the authors, publisher and licensee Libertas Academica Limited. This is an open-access article distributed under the terms of the Creative Commons CC-BY-NC 3.0 License.

CORRESPONDENCE: ana.sanchez@brocku.ca

Paper subject to independent expert single-blind peer review. All editorial decisions made by independent academic editor. Upon submission manuscript was subject to anti-plagiarism scanning. Prior to publication all authors have given signed confirmation of agreement to article publication and compliance with all applicable ethical and legal requirements, including the accuracy of author and contributor information, disclosure of competing incres and funding sources, compliance with ethical requirents comp to human and relating to human and animal study participants, and compliance with any copyright requirements of third parties. This journal is a member of the Committee on Publication Ethics (COPE)

Published by Libertas Academica. Learn more about this journal.

\section{Introduction}

Among the intestinal parasites that infect children in the developing countries, a group of parasitic nematodes, known as soil-transmitted helminths (STH), remain a serious public health problem. ${ }^{1}$ The most prevalent STH species are Ascaris lumbricoides, Trichuris trichiura, and the hookworms, Necator americanus and Ancylostoma duodenale. ${ }^{1}$ As other neglected tropical diseases (NTDs), these infections thrive in conditions of poverty characterized by the lack of safe water, sanitation, and hygiene, and due to their chronicity, they are associated with an insidious impact on the health and quality of life of those infected. ${ }^{2}$ STH can contribute to, or aggravate, malnutrition, ${ }^{3}$ and a poor nutritional status may predispose children to these parasitic infections. ${ }^{4,5}$ To reduce the burden of STH infections in endemic countries, the World Health Organization (WHO) recommends the implementation of mass drug administration (MDA) with benzimidazole drugs to the groups at high risk of infection, particularly schoolchildren, and more recently to preschool children. ${ }^{1}$

Similar to many other countries in Latin America, Honduras is endemic for $\mathrm{STH},{ }^{6}$ and these infections have long been recognized by the government as significant public health problems disproportionally affecting children. ${ }^{7}$ Currently, these parasitoses are among the nine NTDs targeted for prevention and control at the national level. ${ }^{8}$ Yet, despite these efforts and the country's ongoing improvements in major health and social indicators, ${ }^{9}$ according to the WHO, almost 800,000 preschool children and almost two million school-age children are still living at risk of infections (http://www.who.int/neglected_diseases/ preventive_chemotherapy/sth/en/). However, this risk is not equally distributed. Honduras is a country of great inequalities in terms of income distribution, as well as in access to sanitation, safe water, education, health care, and food security, among others..$^{10}$ Differences in poverty and inequalities occur not only at the interdepartmental and intermunicipal levels but also at the intramunicipal level. ${ }^{11}$ In a retrospective analysis, we previously observed significant intermunicipal differences in the prevalence of soil-transmitted helminthiases in Honduras. Increased prevalence was associated with lower Human Development Index (HDI). ${ }^{12}$ Other studies describing the prevalence, health impact, and risk factors of 
STH infections in Honduran schoolchildren have recently been undertaken in the rural populations ${ }^{7,13}$ and across the country's ecological regions. ${ }^{14}$ However, the distribution of STH according to different levels of poverty has not been examined. As Honduras has yet to reach the recommended deworming treatment coverage of at least $75 \%$ of children at risk of infection, ${ }^{1}$ this information may support prioritization of areas, where the prevalence of soil-transmitted helminthiases continues unabated.

The present study is aimed to investigate the prevalence of STH infections among residents of remote rural communities in Honduras, in which health inequalities are well documented..${ }^{15}$ To access such communities, a partnership was established between a team of parasitology researchers from Honduras and Canada and a U.S. multidisciplinary medical relief brigade serving the communities once a year since the last decade. The medical brigade is organized by the nonprofit organization Golden Phoenix Foundation (GPF) and Virginia Commonwealth University's (VCU) Global Health and Health Disparities Program. ${ }^{15}$ Research objectives were to describe among children living in remote impoverished Honduran rural communities: (i) the role of different levels of poverty in STH prevalence and (ii) the potential association of STH infections with malnutrition and anemia.

\section{Methods}

Ethical approval. This study received clearance from the Bioscience Research Ethics Board of the Brock University (file number BU 13-195, dated March 5, 2014) as well as from the Research Ethics Board of the Master's Program in Infectious and Zoonotic Diseases, School of Microbiology, National Autonomous University of Honduras (file number CEI-MEIZ 04-2014, dated June 2, 2014). Informed consent was documented with research participants' signatures or fingerprints on the consent forms that had been fully explained to them. Children's assents were obtained verbally and documented through a child assent form. Each participant received his or her parasitological results within 24 hours on a form that had been adapted to contain both the technical Kato-Katz report, including the egg count and the corresponding interpretations in lay language and hand drawings indicating the types of parasites found, if any. Under agreement with the Ministry of Health, the GPF/VCU team treats all people (children and adults) attending the clinics with a single-dose 400-mg albendazole chewable tablet. In this study, treatment to research participants was given the following day after stool sample examination. According to the WHO's mass deworming strategy, all children were treated, including the Kato-Katz-negative ones. All ethics documentation, laboratory reports, and oral communications were in Spanish language. This study complied with the principles of the Declaration of Helsinki.

Study area and population. Field and laboratory studies were carried out in June 2014 in the municipality of Olanchito, the capital of Department of Yoro, in Northern Honduras. According to the Honduran Ministry of Health, Yoro is situated in the ecological region $\mathrm{II}^{14}$ and possesses an average HDI of 0.689 , ranking 5th among the country's 18 departments (Honduras' national HDI for 2011 was 0.705). ${ }^{11}$

The study communities were all located in a rural mountainous area within the municipality of Olanchito (HDI $=0.697)$. As mentioned earlier, the central community from which the research team operated was La Hicaca $\left(15^{\circ}\right.$ $27^{\prime} 0^{\prime \prime}$ North, $87^{\circ} 2^{\prime} 0^{\prime \prime}$ West (http://www.maplandia.com/ honduras/yoro/olanchito/la-hicaca/).

La Hicaca is a village ("aldea" in Spanish) $65 \mathrm{~km}$ away from the nearest hospital in the city of Olanchito and functions as the core community for 17 smaller, fairly isolated hamlets ("caseríos" in Spanish). According to the last census done by community leaders in 2012, a total of 1,216 people lived in the area, with 245 and 971 people living in La Hicaca and surrounding hamlets, respectively. According to Honduras' population pyramid, the number of children across all these communities is $\sim 423$ (34.8\%). For livelihood, the population relies on subsistence agriculture (beans, corn, chicken, and pigs; a few families own cattle or horses).

Except for one hamlet (Chorro Viento), which owned a hydroelectric power plant, no municipal electricity or water services are available in the area. Water for domestic use is obtained from the nearby river. The inhabitants in La Hicaca and five other hamlets obtain water without treatment from the communal cisterns for distribution via a rudimentary pipes network, while the inhabitants in the remaining hamlets collect the water directly from the river or streams.

There are public primary schools (grades 1-6) in all the communities except one (La Veguita), but in El Urraco, the school is often closed for lack of teachers. The closest high school is located in the municipal capital. A primary healthcare center staffed with one nurse holding a university degree is located in La Hicaca, but substantial gaps in access to health care have been reported for all communities. ${ }^{15}$ Travel time to the health-care center for people living in the surrounding hamlets varies between three and seven hours by foot, the most common mode of transportation. Travel time depends on not only distance but also on topographical features and road conditions. ${ }^{15}$

Poverty levels in the study communities. Information on the intensity of poverty in the study communities was obtained from a health and poverty analysis report done in 2006 by the local staff of the Ministry of Health (unpublished). To assess poverty, this study used the unsatisfied basic needs (UBN) method, a household-based approach commonly utilized in the developing countries. UBN collects the physical characteristics of the households: materials used to build as well as the condition of walls and floors, access to potable water and sewage disposal services, the number of rooms and people living in the house, and the number of school-aged children not attending school. Households are categorized 
using a scale from 0 to $5 \mathrm{UBN}$ as follows: 0 , not poor; at least 1 UBN, poor; and $>1$ UBN, extremely poor. ${ }^{9}$ The health and poverty analysis found that not only all households had $>1$ UBN (hence, extremely poor) but the majority also had $>3$ UBN. A poverty map was created for the report by grouping the communities into four poverty strata based on the proportion of households with $\geq 3$ UBN. Therefore, strata I, II, III, and IV of the communities consisted of up to $44 \%, 45-62 \%$, 63-80\%, and $81-100 \%$, of households, respectively, with $\geq 3$ UBN. As UBN-based poverty nomenclature does not distinguish beyond $>1$ UBN, for comparative analysis in the present study, we grouped the communities into two levels of poverty: less poor (ie, with fewer UBNs; strata I-II) and poorest (ie, with more UBNs; strata III-IV).

Data collection. Participant's demographic and epidemiological data were collected using a five-minute, faceto-face questionnaire administered in Spanish to parents/ guardians. Aside from personal identifiers, questions were related to deworming history, household conditions (possession of latrine or toilet; type of floor, with separate questions for kitchen, bedroom, and living room; and access to and type of water), and owning domestic animals.

Assessment of nutritional status. Children's nutritional status was assessed through anthropometric indicators, as previously reported. ${ }^{7}$ Stunting, underweight, and thinness were determined when children's height-for-age Z-score (HAZ), weight-for-age Z-score (WAZ), and body-mass-index-for-age $Z$-score (BAZ) were $<-2$ standard deviations (SDs) of reference values, respectively. ${ }^{16}$ According to the standards, WAZ was calculated only for children $\leq 10$ years of age. ${ }^{16}$

Hemoglobin $(\mathrm{Hb})$ values were determined using the HemoCue Hb 201+ system (HemoCue AB). Capillary blood samples were taken by the GPF/VCU pediatric team. $\mathrm{Hb}$ concentrations were determined following the protocol of HemoCue AB. As communities were situated $<1,000 \mathrm{~m}$ above sea level, $\mathrm{Hb}$ values did not require adjustment. ${ }^{17}$ Anemia was determined based on $\mathrm{Hb}$ values in $\mathrm{g} / \mathrm{dL}$ and classified as mild, moderate, or severe according to the parameters established in the most recent Demographic and Health Survey in Honduras (DHS-HN) for 2011-2012 ${ }^{18}$ as follows:

(i) Children 7-23 months of age: mild $\leq 10.9 \mathrm{~g} / \mathrm{dL}$; moderate $\leq 8.9 \mathrm{~g} / \mathrm{dL}$; and severe $\leq 5.9 \mathrm{~g} / \mathrm{dL}$.

(ii) Children $24-60$ months of age: mild $\leq 11.4 \mathrm{~g} / \mathrm{dL}$; moderate $\leq 9.4 \mathrm{~g} / \mathrm{dL}$; and severe $\leq 6.4 \mathrm{~g} / \mathrm{dL}$.

(iii) Children $>60$ months of age: mild $\leq 11.9 \mathrm{~g} / \mathrm{dL}$; moderate $\leq 10.0 \mathrm{~g} / \mathrm{dL}$; and severe $<7 \mathrm{~g} / \mathrm{dL}$.

Stool collection and parasite determination. A single stool sample was obtained from the research participants to determine the presence and intensity of STH infection using the Kato-Katz method, as recommended by the $\mathrm{WHO},{ }^{1}$ with a 41.7-mg template (Vestergaard Frandsen SA). Samples were brought by participants the same day of collection. As neither electricity nor a suitable place to prepare and observe stool samples in the field was available, samples were kept in portable coolers and transported to Olanchito's public hospital clinical laboratory (a one-hour drive from La Hicaca). Hence, samples were examined for parasites the same day of collection in the late afternoon and evening hours once the laboratory became available. The time for preparing the Kato-Katz thick smear from the sample collection was about six to eight hours. Kato-Katz smears were microscopically examined within 30-60 minutes of preparation. Helminth eggs were identified by their characteristic features and systematically counted to estimate the number of eggs per gram of stools in order to classify infections as light, moderate, or heavy intensity, as per the WHO criteria. ${ }^{1}$ For quality control, $10 \%$ of positive and $100 \%$ of negative smears were reread by a different researcher immediately after the first reading. Polyparasitism was defined as the presence of more than one helminth species in the sample. Due to logistic constraints, investigating other parasites-such as Strongyloides stercoralis, for which Kato-Katz is not suitable-and intestinal protozoa was not attempted.

Data management and statistical analysis. Data from questionnaires, anthropometric measurements, and KatoKatz results were entered into a spreadsheet (Microsoft Office Excel 2010) by a researcher. A second researcher verified the data for accuracy (compared with the data in the questionnaires and laboratory reports) and checked for missing and outlier values. Research participants were assigned a poverty group according to their community of residence (ie, less poor or poorest), as described earlier. The study population was characterized using descriptive statistics (frequency, cumulative frequency, percentages, means, and SDs). Point prevalences with $95 \%$ confidence intervals $(95 \% \mathrm{CI})$ were calculated for overall STH infections and for each STH species. Similarly, point prevalences with 95\% CI were calculated for polyparasitic STH infections. Anthropometric indicators were calculated using the WHO AnthroPlus software (WHO) version 1.04 for children aged $\geq 5$ years and version 3.2.2 for those aged $<5$ years (software is available at http://www.who. int/growthref/tools/en/).

Differences in proportions were calculated for categorical variables using chi-square test of independence or Fisher's exact test, whereas differences in mean values for continuous variables were assessed using Student's $t$-test analysis.

Associations between nutritional indicators and parasite infections and between parasite infections and sociodemographic characteristics were explored through univariate and multivariable logistic regression models. Unadjusted and adjusted odds ratio (OR) with 95\% CI were determined, and the level of significance was defined as $P<0.05$. Statistical analyses were conducted using Stata 13 (StataCorp LP). Clustering effect (potential within-community data correlation) was controlled by using the command "vce(cluster)" in Stata. 


\section{Results}

A total of 130 children from 10 communities with age ranging from 0.7 to 13.3 years $(M=6.77 ; \mathrm{SD}=3.29)$ participated in this study.

Seventy-six (58.5\%) children resided in less poor communities (ie, La Hicaca, La Florida, Agua Caliente, and La Esperanza), whereas 54 (41.5\%) were living in the poorest communities (ie, Lomitas, Carmelita, El Urraco, Agua Sarca, Santa María, and El Portillo 1). Being the core area, La Hicaca had better infrastructure: a functional health-care center, a spacious four-classroom primary school, a good number of households built out of adobe bricks and clay tile or tin roofs, latrines in almost $80 \%$ of households, intermittent cell phone reception, and since very recently better road access to the municipal capital. Notwithstanding these better conditions, serious problems related to inadequate sanitation, garbage accumulation, and environmental degradation were observed. In addition, freeroaming domestic animals—such as pigs, dogs, cattle, and chicken-cause conspicuous fecal contamination throughout the village. At the time of this study, it was observed that the health-care center was well stocked with anthelmintic drugs, mainly albendazole and piperazine. In addition, the Healthy Schools Program, which operates the deworming program in Honduras,${ }^{14}$ had provided albendazole tablets in April 2014. The surrounding hamlets were in considerably worse conditions in all the abovementioned aspects compared to La Hicaca. In addition, it was observed that the poorest communities were located farther away from the health-care center.

Table 1 summarizes the key characteristics of the study population by poverty group. There were no statistical

Table 1. Characteristics and parasitological findings of the study population by poverty group.

\begin{tabular}{|c|c|c|c|c|}
\hline CHARACTERISTICS ${ }^{a}$ & $\begin{array}{l}\text { ALL CHILDREN } \\
n=130\end{array}$ & $\begin{array}{l}\text { POVERTY GROUP } \\
\text { LESS POOR } n=76\end{array}$ & $\begin{array}{l}\text { POVERTY GROUP } \\
\text { POOREST } n=54\end{array}$ & P-VALUEb \\
\hline Age-mean $(S D)$ & $6.77(3.29)$ & $6.54(3.21)$ & $7.08(3.41)$ & 0.365 \\
\hline Girls & $53.8 \%$ & $55.3 \%$ & $51.8 \%$ & 0.701 \\
\hline \multicolumn{5}{|l|}{ Household conditions } \\
\hline Earthen floor (complete or partial) & $85.4 \%$ & $81.6 \%$ & $90.7 \%$ & 0.145 \\
\hline No latrine or toilet & $36.1 \%$ & $22.4 \%$ & $55.6 \%$ & $<0.001$ \\
\hline No access to piped water & $53.1 \%$ & $22.4 \%$ & $96.3 \%$ & $<0.001$ \\
\hline \multicolumn{5}{|l|}{ Parasitic profile } \\
\hline Overall prevalence of STH infections & $69.2 \%$ & $61.8 \%$ & $79.6 \%$ & 0.030 \\
\hline Ascaris lumbricoides & $12.31 \%$ & $6.6 \%$ & $20.4 \%$ & 0.018 \\
\hline Trichuris trichiura & $69.2 \%$ & $61.8 \%$ & $79.6 \%$ & 0.030 \\
\hline Hookworms & $3.85 \%$ & $3.9 \%$ & $3.7 \%$ & 0.943 \\
\hline Polyparasitic infections $(n=90)$ & $21.1 \%$ & $14.9 \%$ & $27.9 \%$ & 0.131 \\
\hline Moderate-to-heavy infections by $A$. Iumbricoides $(n=16)$ & $50.0 \%$ & $60.0 \%$ & $45.4 \%$ & 0.590 \\
\hline Moderate-to-heavy infections by T. trichiura $(n=90)$ & $23.3 \%$ & $27.7 \%$ & $18.6 \%$ & 0.310 \\
\hline Moderate-to-heavy infections by hookworms $(n=51)$ & $0.0 \%$ & $0.0 \%$ & $0.0 \%$ & - \\
\hline \multicolumn{5}{|l|}{ Practices and STH history } \\
\hline Owning pigs $(n=129)^{\mathrm{d}}$ & $73.6 \%$ & $69.7 \%$ & $79.2 \%$ & 0.228 \\
\hline Owning dogs $(n=129)^{\mathrm{d}}$ & $79.8 \%$ & $78.9 \%$ & $81.1 \%$ & 0.761 \\
\hline Recalled previous deworming & $86.1 \%$ & $92.1 \%$ & $77.8 \%$ & 0.020 \\
\hline \multicolumn{5}{|l|}{ Nutritional indicators } \\
\hline Height-for-age score (HAZ)—mean (SD) & $-1.35(1.30)$ & $-1.51(1.28)$ & $-1.14(1.31)$ & 0.112 \\
\hline Weight-for-age score (WAZ)_mean $(S D)(n=108)^{\mathrm{c}}$ & $-0.62(1.11)$ & $-0.74(1.12)$ & $-0.45(1.08)$ & 0.192 \\
\hline Body mass index-for-age score (BAZ)—mean (SD) & $0.25(0.96)$ & $0.27(0.96)$ & $0.22(0.95)$ & 0.768 \\
\hline Stunted $(<-2$ SD HAZ) & $30.0 \%$ & $35.5 \%$ & $22.2 \%$ & 0.103 \\
\hline Underweight/Thin (<-2 SD WAZ/<-2 SD BAZ) & $11.1 \%$ & $13.8 \%$ & $7.0 \%$ & 0.266 \\
\hline Overweight ( $>1$ SD \& <=2 SD BAZ) & $17.7 \%$ & $56.5 \%$ & $43.5 \%$ & 0.835 \\
\hline Obese ( $>2$ SD BAZ) & $3.8 \%$ & $80.0 \%$ & $20.0 \%$ & 0.319 \\
\hline Hemoglobin $(\mathrm{g} / \mathrm{dL})$-mean $(S D)(n=116)^{\mathrm{d}}$ & $11.2(1.28)$ & $10.89(1.42)$ & $11.59(0.94)$ & 0.003 \\
\hline Anemia $(n=116)$ & $69.0 \%$ & $75.8 \%$ & $60.0 \%$ & 0.069 \\
\hline
\end{tabular}

Notes: ${ }^{a}$ For each characteristic, $n=130$ unless otherwise stated. ${ }^{b} P$-values were calculated by the $t$-test for continuous variables and chi-square test or Fisher's exact test for categorical variables. 'Weight for age was not calculated for children older than 10 years of age. ${ }^{\mathrm{d} M i s s i n g}$ data (14 children not tested due to the shortage of reagents)

Abbreviation: STH, soil-transmitted helminth. 
differences in children's age and gender when such groups were compared ( $P=0.365$ and $P=0.701$, respectively). T. trichiura was the more prevalent helminth by far, with an overall prevalence of $69.2 \%$ (95\% CI: 60.7-76.6) followed by A. lumbricoides with $12.3 \%$ (95\% CI: 7.6-19.2) and hookworms with 3.8\% (95\% CI: 1.6-9.0). The prevalence of polyparasitism was $21.1 \%$ (95\% CI: $13.8-30.9)$. No other helminth diagnostic stage was observed in the Kato-Katz preparations.

Although STH prevalence in each poverty group was exceedingly high, children living in the poorest conditions were significantly more parasitized and received deworming medication less frequently than those residing in less poor communities.

Table 1 also shows that $30 \%$ of the studied children were chronically malnourished (stunted growth), whereas $11 \%$ were underweight. Conversely, $17.7 \%$ were overweight and $3.8 \%$ were obese. Coexisting nutritional deficiencies are not shown in Table 1, but it is important to mention that stunting was observed concurrently with underweight $(n=11)$, overweight $(n=2)$, and obesity $(n=4)$. All the children categorized as obese $(n=5)$ were also stunted and were under five years of age (Table 2). No statistical differences were observed in the nutritional indicators between the poverty groups.

Anemia was detected in $69 \%$ of 116 children tested (the remaining 14 were not tested due to the shortage of reagents). It was further classified as light and moderate in $83.75 \%$ and $16.25 \%$ of children, respectively. No severe cases of anemia were found. Although no difference was observed in the prevalence of anemia between the poverty groups, a statistically significant difference in the mean $\mathrm{Hb}$ concentration between the groups was documented ( $P=0.03$; Table 1$)$.

Table 2 presents a comparison of the nutritional status and parasitic profile of children up to five years of age versus those five years of age or older.

Nutritional indicators were not statistically different among the age groups, except for obesity. In terms of parasitism, a greater proportion of older children were infected by any STH than their younger counterparts $(P=0.003)$, with the difference being due to T. trichiura infection $(P=0.003)$. Moreover, compared with younger children, a greater proportion of older children had received deworming treatment, according to their parents $(P=0.036)$.

When associations were explored between nutritional indicators and parasitism, no statistical associations were found between infection with any STH and stunting, underweight, or anemia $(P=0.104, P=0.884$, and $P=0.563$, respectively). Similarly, no statistically significant associations could be found between the nutritional indicators and deworming history $(P=0.1782, P=0.915$, and $P=0.174$, respectively).

Associations between infection with any STH and with polyparasitism and demographic and epidemiological characteristics were assessed through univariate and multivariable logistic regression models controlling for cluster effect. The results of these analyses are detailed in Table 3.

Table 2. Nutritional indicators and parasitic profile of the study population by age group.

\begin{tabular}{|c|c|c|c|}
\hline \multirow[t]{2}{*}{ CHARACTERISTICS $^{a}$} & \multicolumn{2}{|l|}{ AGE } & \multirow[t]{2}{*}{ P-VALUE ${ }^{b}$} \\
\hline & 6-59 MONTHS $n=44$ & $60+$ MONTHS $n=86$ & \\
\hline \multicolumn{4}{|l|}{ Nutritional indicators } \\
\hline Stunted $(<-2$ SD HAZ) & $34.1 \%$ & $27.9 \%$ & 0.467 \\
\hline Underweight/Thin $(<-2$ SD WAZ/<-2 SD BAZ) $(n=108)$ & $13.6 \%$ & $9.4 \%$ & 0.489 \\
\hline Overweight ( $>1$ SD \& <=2 SD BAZ) & $25.0 \%$ & $13.9 \%$ & 0.118 \\
\hline Obese (>2 SD BAZ) & $11.4 \%$ & $0.0 \%$ & 0.001 \\
\hline Anemia $(n=116)$ & $34.5 \%$ & $65.5 \%$ & 0.899 \\
\hline - Mild anemia & $55.0 \%$ & $59.2 \%$ & - \\
\hline - Moderate anemia & $12.5 \%$ & $10.5 \%$ & - \\
\hline \multicolumn{4}{|l|}{ Parasitic profile } \\
\hline Overall prevalence of STH infections & $52.3 \%$ & $77.9 \%$ & 0.003 \\
\hline Ascaris lumbricoides & $11.4 \%$ & $12.8 \%$ & 0.815 \\
\hline Trichuris trichiura & $52.3 \%$ & $77.9 \%$ & 0.003 \\
\hline Hookworms & $2.3 \%$ & $4.6 \%$ & 0.505 \\
\hline Multiple species infection (polyparasitism) $(n=90)$ & $26.1 \%$ & $19.4 \%$ & 0.498 \\
\hline Moderate-to-heavy infections by $A$. lumbricoides $(n=16)$ & $40.0 \%$ & $54.5 \%$ & 0.590 \\
\hline Moderate-to-heavy infections by T. trichiura $(n=90)$ & $21.7 \%$ & $23.9 \%$ & 0.834 \\
\hline Moderate-to-heavy infections by hookworms $(n=51)$ & $0.0 \%$ & $0.0 \%$ & - \\
\hline Recalled previous deworming & $77.3 \%$ & $90.7 \%$ & 0.036 \\
\hline
\end{tabular}

Notes: ${ }^{a}$ For each characteristic, $n=130$ unless otherwise stated. ${ }^{b} P$-values were calculated by the chi-square test or Fisher's exact test. Abbreviation: STH, soil-transmitted helminth. 
Table 3. Association between parasitic infections and observed sociodemographic characteristics of the study population.

\begin{tabular}{|c|c|c|c|c|c|c|c|c|}
\hline \multirow[t]{2}{*}{ VARIABLES } & \multicolumn{4}{|c|}{ STH INFECTION WITH ANY SPECIES $(n=130)$} & \multicolumn{4}{|c|}{ POLYPARASITISM $(n=130)$} \\
\hline & OR $(95 \% \mathrm{CI})$ & P-VALUE & adjOR $(95 \% \mathrm{Cl})$ & $\overline{P \text { P.VALUE }}$ & OR $(95 \% \mathrm{CI})$ & P-VALUE & adjOR $(95 \% \mathrm{Cl})$ & P-VALUe \\
\hline Age (years) & $1.11(1.03-1.20)$ & 0.006 & $1.08(0.97-1.20)$ & 0.157 & $0.96(0.87-1.06)$ & 0.447 & $0.94(0.84-1.06)$ & 0.321 \\
\hline Sex (boys) & $1.24(0.53-2.88)$ & 0.621 & $0.97(0.32-2.53)$ & 0.952 & $1.35(0.39-4.72)$ & 0.633 & $1.29(0.33-5.04)$ & 0.712 \\
\hline $\begin{array}{l}\text { Recalled deworming } \\
\text { (yes) }\end{array}$ & $0.85(0.33-2.18)$ & 0.730 & $0.90(0.32-2.53)$ & 0.842 & $0.54(0.12-2.47)$ & 0.429 & $0.72(0.22-2.37)$ & 0.590 \\
\hline $\begin{array}{l}\text { Earthen floor at } \\
\text { home (total or partial) }\end{array}$ & $6.74(2.67-17.03)$ & $<0.001$ & $4.73(2.18-10.24)$ & $<0.001$ & $3.48(0.96-12.70)$ & 0.001 & $2.94(0.39-22.41)$ & 0.297 \\
\hline Latrine (none) & $3.77(1.74-8.15)$ & 0.001 & $2.48(0.71-8.61)$ & 0.153 & $3.72(1.69-8.20)$ & 0.001 & $2.80(1.21-6.47)$ & 0.016 \\
\hline $\begin{array}{l}\text { Piped water at } \\
\text { home (no) }\end{array}$ & $3.42(1.27-9.18)$ & 0.015 & $2.10(0.62-7.15)$ & 0.234 & $2.85(1.35-6.00)$ & 0.006 & $1.83(0.84-3.99)$ & 0.131 \\
\hline $\begin{array}{l}\text { Poverty group } \\
\text { (poorest) }^{a}\end{array}$ & $2.41(0.72-8.07)$ & 0.153 & - & - & $2.82(1.49-5.30)$ & 0.001 & - & - \\
\hline
\end{tabular}

Note: axcluded from multivariable analysis because this variable is constructed using the UBN criteria, which includes some of the household conditions in the model.

Abbreviations: STH, soil-transmitted helminth; OR, odds ratio from univariate analysis; adjOR, adjusted odds ratio from multivariable analysis.

As shown in Table 3, the compound variable poverty group was excluded from the multivariable analyses because, as explained earlier, it was constructed using UBN criteria, which includes household conditions included in the model (for instance, poverty group showed high collinearity with absence of piped water and moderate collinearity with absence of latrine).

At the univariate level, age, earthen floor at home, absence of latrine, and lack of piped water were significantly associated with overall infection-by any of the parasite species investigated. However, in the multivariable model, these associations weakened, and household's earthen floor was the only variable that remained significant $(\mathrm{OR}=4.73 ; 95 \% \mathrm{CI}$ : 2.18-10.24; $P<0.001)$. Similarly, polyparasitism was also significantly associated, at the univariate level, with several of the variables tested, of which only absence of latrine remained statistically significant $(P=0.016)$.

\section{Discussion}

Poverty, geography, and parasites. The present study was undertaken in communities previously defined as extremely poor, but our study shows that the levels of poverty were a function of geography: the poorest communities were located farther away from the health-care center and their children harbored more parasites than their less poor counterparts. They also were less likely to have received deworming medication at all. These findings coincide with other studies not only highlighting the importance of geographical accessibility to health care in Honduras ${ }^{15,19}$ but also demonstrating that among the poor, those residing in remote rural communities face an even greater risk of STH infection. ${ }^{20,21}$

Despite their challenges, it was encouraging to find that these communities had greater deworming treatment coverage than the country as a whole. For example, the latest DHS-HN survey reports that only $55 \%$ of Honduran children 6-59 months of age had received deworming treatment in the six months prior to the survey. ${ }^{18}$ Similarly, in 2014 , the Honduras Ministry of Health reported national deworming coverage of $19.99 \%$ and $59.48 \%$ for preschool and schoolchildren, respectively (data generated at: http://www.who.int/ neglected_diseases/preventive_chemotherapy/sth/en/).

This increased deworming coverage in the study communities is likely due to the combined efforts of the healthcare center nurse and GPF/VCU brigades. Yet, an overall STH prevalence of $69.2 \%$ qualifies La Hicaca and hamlets as bigh-risk areas, for which intensified STH control efforts are needed, including biannual deworming ${ }^{1}$ and improvements in water, sanitation, and hygiene education. ${ }^{22}$ Moreover, the high proportion of moderate-to-heavy $A$. lumbricoides and T. trichiura infections found suggests that $\mathrm{STH}$-associated morbidity could be significant in this population. ${ }^{1}$

Another highlight of the present study is the identification of T. trichiura as the dominant helminth species over A. lumbricoides. Similar observations are reported by other community-based studies ${ }^{13}$ as well as by the latest Honduran national STH survey. ${ }^{14}$ The low efficacy of a single-dose albendazole for T. trichiura is the most likely explanation for this phenomenon. ${ }^{23}$ However, it is important to remain vigilant for the emergence of benzimidazole resistance in this parasite. ${ }^{21}$

Finally, when an analysis was done by an age-group with a cutoff at five years of age, some expected associations were found: (1) older children were more parasitized, as they are more likely exposed by both virtue of their age and contact with the environment; (2) younger children, being preschoolers, are dewormed less frequently, which is congruent with the fact that the WHO's recommendation to deworm all children is fairly recent. However, an unexpected finding was that the proportion of moderate-to-heavy infections in both the age groups showed no statistical difference. As a higher worm burden is associated with higher morbidity, this finding suggests that intervention programs need to pay attention to preschoolers as well. 
Stunting and anemia. Our data also reveal an exceptionally high proportion of chronic malnutrition $(30 \%$ stunting), higher than both the national (23\%) and regional averages (26\%). ${ }^{18}$ Although protein-energy malnutrition has been identified as a pervasive problem in Honduras, ${ }^{24,25}$ reporting community-based data helps understand withincountry differences that, according to Lutter et al, "are most pronounced in the case of stunting." ${ }^{24}$ Indeed, identifying inequalities within countries is required to prioritize the most disadvantaged. ${ }^{20}$ Stunting in children is the result of multigenerational conditions affecting both mother and child, ${ }^{25}$ and its causality is compounded by a number of distal and proximal factors, ${ }^{25,26}$ including continued exposure to fecally contaminated environments. ${ }^{27}$ However, it is important to keep in mind that intestinal parasites also have deleterious effects in children's nutrition ${ }^{3,28}$ For this reason, intestinal parasites, including STH, need to be controlled below the levels of morbidity, if not eliminated.

The prevalence of anemia (69\%) among study children was above national averages ${ }^{29}$ and at such level, it is considered a severe public health problem. Parasitic diseases may play a role in the etiology of anemia, particularly where the transmission of malaria or hookworm is intense, ${ }^{2,29}$ but the study area is not endemic for malaria ${ }^{14}$ and the prevalence of hookworm infection was low (3.85\%). Thus, the findings of the current study do not support an association between anemia and STH infection. Many underlying factors may be contributing to anemia in this population, micronutrient deficiencies, for instance, which have been demonstrated as pervasive in Honduras. ${ }^{30} \mathrm{An}$ interesting finding worth mentioning is that children grouped in the poorest category presented statistically significant higher mean $\mathrm{Hb}$ values than their less poor counterparts. Although poverty and food insecurity are tightly associated, our study did not measure the differences in availability and quality of food between the poverty groups. Hence, it cannot be concluded that the poorest have worse diets than the comparison group. In addition, these seemingly paradoxical findings are not unusual. For example in Tanzania, individuals infected with $\geq 1$ helminth species were not at higher risk of anemia than those not infected, and people living in a peri-urban setting had higher prevalence of anemia than those living in a rural area. ${ }^{31}$ Furthermore, in a recent study of anemia prevalence across 34 countries, including Honduras, Yasutake et al found high levels of anemia in the wealthiest households, with countries, such as Honduras, showing little variance by wealth. ${ }^{32}$ The upside of this finding - according to the authors-is that instead of targeting specific groups, interventions to decrease anemia should be done at the population level, which is easier and more attractive. This too could be a feasible strategy for the population participating in the present study.

The levels of stunting and anemia among study participants are of public health concern. ${ }^{25,32}$ Thus, these results have been conveyed to community leaders and local public health authorities.
Associations between parasitism and deworming with nutritional indicators. Contrary to our expectations, the present study could not demonstrate an association between nutritional indicators and parasitism. Discordant results are not rare in the literature, and in fact, Tanner recently reported on the difficulties of finding clear associations between parasitic infections and nutritional outcomes when both the conditions are ubiquitous among study populations. ${ }^{5}$ Our findings coincide with those of a Mexican study that detected statistically significant associations between malnutrition and parasitism in some highly endemic communities, but not in others. ${ }^{33}$

The lack of association between prior deworming and nutritional indicators is not surprising either, as scientific evidence on the benefit of MDA is still under debate. ${ }^{34}$ Studies in other countries suggest that the impact of deworming in endemic areas is likely undermined by other widespread infectious diseases and nutritional deficiencies. ${ }^{35}$ This needs to be studied in Honduras.

Factors associated with parasitism prevalence. The multivariable models were able to detect two important associations. First, infection with any STH was significantly associated with household's earthen floor. Second, polyparasitism was significantly associated with lack of latrines in the home. Although it is well known that these physical conditions are essential for STH-sustained transmission, ${ }^{36,37}$ our findings highlight the importance of improving sanitary conditions in the study communities. Based on this information, the VCU team and community leaders have already launched a plan to install latrines in $100 \%$ of the households in the next two years.

Study limitations and strengths. The study relies on a small convenience sample with not enough statistical power, which may have hindered the identification of more factors associated with STH prevalence. Due to the study's crosssectional design, seasonal factors influencing parasitism and nutritional status among the studied children could not be revealed. Self-reporting of households' conditions and parents' recall of their children's deworming treatment may have introduce errors in our data.

Furthermore, a selection bias may have occurred if participating children were enrolled by their parents due to concerns about parasitic infections. If this was the case, an overestimation of STH prevalence may have occurred. An additional limitation is the lack of information regarding research participants' time of residence in their home communities and the extent of contact between the communities. More importantly, as the UBN characterization of poverty does not take into account nutritional variables, differences in supply and quality of food between the poverty groups could not be determined.

Despite these limitations, our study has several strengths. To begin, this is the first report to examine STH prevalence among populations living in remote rural communities. Several recent studies describe STH prevalence data from populations accessible from main municipal roads and therefore 
with more access to health services and deworming. Findings from such studies fail to represent the most disenfranchised sectors of the Honduran population. Second, unlike other studies, the present study enrolled children younger than five years of age. We show that a significant proportion of preschool children are already infected with STH and are likely a source of infection for other age groups, as previously noted by others. ${ }^{38}$ Third, we have taken into account the differences in poverty levels among already impoverished communities. The majority of studies in Honduras and elsewhere have not examined these important differences. Finally, to present meaningful data to the country's STH control strategies, we utilized methodology and definitions of anemia similar to those reported by the latest DHS-HN. In addition, we based our poverty analysis on UBN, a method, widely utilized in Honduras and Latin America. ${ }^{39,40}$ Although measuring poverty in the developing world is complicated and there exists an ongoing quest to find better ways to capture all of its dimensions, ${ }^{39}$ UBN is considered the most objective method that permits detecting small changes missed by other methodologies (such as methods based on income, assets, and expenditures). ${ }^{9}$

Our study adds to the body of literature on STH burden in Honduras and Central America. Future research should examine the role of spatial accessibility to health care in health outcomes, including nutrition and parasitic infections. In addition, identifying barriers and facilitators to medical or environmental intervention that are often implemented in STH-endemic communities is essential. We agree with Chambers and von Medeazza who continue to encourage the scientific community to take a closer look into interactions between open defecation and fecally transmitted infections with childhood undernutrition. ${ }^{27}$

A novel aspect of this study is the collaborative partnership between STH researchers and medical relief efforts reaching the remote communities. This was an efficient and cost-beneficial strategy and, in our opinion, could be valuable for continuing mapping out STH prevalence and children's nutrition in the country.

\section{Conclusions}

Honduras aims to reach the recommended target of providing annual or biannual deworming medications to at least $75 \%$ of children living at risk of STH infection in the country. However, as coverage continues to expand, identifying sectors of the population left behind by such initiatives is warranted. Our results show that remote rural communities are susceptible to inequalities with respect to their poverty, geography, and a number of other underlying factors leading to concerning levels of parasitism, anemia, and malnutrition. The situation in La Hicaca and surrounding hamlets underscores the need for integrated multisectoral interventions aimed to not only reduce STH morbidity in endemic areas but also improve the nutritional status of their people, facilitate access to health care, and ensure safe water, sanitation, and hygiene for all.

\section{Acknowledgments}

We would like to thank Golden Phoenix Foundation for their generous donation of medical supplies. We are grateful to Dr. Héctor Mendez, Director of the Clinical Laboratory at Olanchito Public Hospital, for providing laboratory space to process stool samples and to Quest for providing $\mathrm{Hb}$ tests. We would like to thank Rotnny Ferrera, Kiani Canales, and Mauren Antúnez for their assistance during the field and laboratory work. Community leaders are specially thanked for their invaluable contribution in organizing the communities, especially Father Pedro Hernández O'Hagan of the Catholic Dioceses and Rosa Muñoz Rodríguez, staff nurse at La Hicaca Primary Healthcare Center.

\section{Author Contributions}

Conceived and designed the study: ALS, MC, GB, and MPS. Implemented the study: ALS, MC, MMR, MPS, and PWM. Contributed reagents/materials/analysis tools: PWM and GAF. Analyzed the data: ALS, JAG, GAF, GB, MPS, and PWM. Wrote the manuscript: ALS and JAG. All the authors revised the manuscript and provided important intellectual content; all the authors read and approved the final version of the manuscript.

\section{REFERENCES}

1. WHO. Soil-Transmitted Helminthiases: Eliminating Soil-Transmitted Helminthiases as a Public Health Problem in Children. Progress Report 2001-2010 and Strategic Plan 2011-2020. Geneva: World Health Organization; 2012.

2. Hall A. Micronutrient supplements for children after deworming. Lancet Infect Dis. 2007;7(4):297-302.

3. Crompton DWT, Nesheim M. Nutritional impact of intestinal helminthiasis during the human life cycle. Annu Rev Nutr. 2002;22(1):35-59.

4. Papier K, Williams GM, Luceres-Catubig R, et al. Childhood malnutrition and parasitic helminth interactions. Clin Infect Dis. 2014;59(2):234-243.

5. Tanner $S$. Health and disease: exploring the relation between parasitic infections, child nutrition status, and markets. Am J Phys Anthropol. 2014;155(2):221-228.

6. Hotez PJ, Woc-Colburn L, Bottazzi ME. Neglected tropical diseases in Central America and Panama: review of their prevalence, populations at risk and impact on regional development. Int J Parasitol. 2014;44(9):597-603.

7. Sanchez AL, Gabrie JA, Usuanlele MT, Rueda MM, Canales M, Gyorkos TW. Soil-transmitted helminth infections and nutritional status in school-age children from rural communities in Honduras. PLoS Negl Trop Dis. 2013;7(8):e2378.

8. Honduras Ministry of Health. [Strategic Plan for the Prevention, Attention, Control and Elimination of Neglected Infectious Diseases in Honduras (PEEDH). 2012-2017]. Tegucigalpa: Honduras Ministry of Health; 2012.

9. FOSDEH-Foro Social de la Deuda Externa y Desarrollo de Honduras. [Honduras Poverty Analysis. Characterization and Determinants, 2013-2014]. Tegucigalpa: Foro Social de la Deuda Externa y Desarrollo de Honduras; 2014.

10. Tolson DJ, Kemmer TM, Lynch J, et al. Identifying children at risk for nutritional crisis in rural Honduras. J Hunger Environ Nutr. 2010;5(1):13-22.

11. United Nations Development Programme. [Human Development Report Honduras 2011. Reducing Inequity: An Unpostponable Challenge]. Tegucigalpa: United Nations; 2012.

12. Sanchez AL, Gabrie JA, Rueda MM, Mejia RE, Bottazzi ME, Canales M. A scoping review and prevalence analysis of soil-transmitted helminth infections in Honduras. PLoS Negl Trop Dis. 2014;8(1):e2653.

13. Gabrie JA, Rueda MM, Canales M, Gyorkos TW, Sanchez AL. School hygiene and deworming are key protective factors for reduced transmission of soiltransmitted helminths among schoolchildren in Honduras. Parasit Vectors. 2014; 7:354.

14. Mejia RE, Franco DN, Fontecha GA, et al. Prevalence and Intensity of soiltransmitted helminthiasis, prevalence of malaria and nutritional status of school going children in Honduras. PLoS Negl Trop Dis. 2014;8(10):e3248.

15. Pearson CA, Stevens MP, Sanogo K, Bearman GM. Access and barriers to healthcare vary among three neighboring communities in northern Honduras. Int J Family Med. 2012;2012:298472. 
16. de Onis M, Onyango AW, Borghi E, Siyam A, Nishida C, Siekmann J. Development of a WHO growth reference for school-aged children and adolescents. Bull World Health Organ. 2007;85(9):660-667.

17. WHO. Haemoglobin Concentrations for the Diagnosis of Anaemia and Assessment of Severity. Geneva: Vitamin and Mineral Nutrition Information System, WHO; 2011.

18. Honduras Ministry of Health, National Institute of Statistics, ICF International. [Demographic and Health Survey 2011-2012]. Tegucigalpa: Honduras Ministry of Health, National Institute of Statistics, ICF International; 2013.

19. Baker JB. Examining Spatial Patterns of Primary Health Care Utilization in Southern Honduras. Cincinnati: Geography, University of Cincinnati; 2005.

20. Colston J, Saboya M. Soil-transmitted helminthiasis in Latin America and the Caribbean: modelling the determinants, prevalence, population at risk and costs of control at sub-national level. Geospat Health. 2013;7(2):321-340.

21. Halpenny CM, Paller C, Koski KG, Valdés VE, Scott ME. Regional, household and individual factors that influence soil transmitted helminth reinfection dynamics in preschool children from rural indigenous Panama. PLoS Negl Trop Dis. 2013;7(2):e2070.

22. Grimes JE, Croll D, Harrison WE, Utzinger J, Freeman MC, Templeton MR. The role of water, sanitation, and hygiene in reducing schistosomiasis: a review. Parasit Vectors. 2015;8(1):156.

23. Keiser J, Utzinger J. Efficacy of current drugs against soil-transmitted helminth infections: systematic review and meta-analysis.JAMA. 2008;299(16):1937-1948.

24. Lutter CK, Chaparro CM, Muñoz S. Progress towards Millennium Development Goal 1 in Latin America and the Caribbean: the importance of the choice of indicator for undernutrition. Bull World Health Organ. 2011;89(1):22-30.

25. De Onis M, Blössner M, Borghi E. Prevalence and trends of stunting among pre-school children, 1990-2020. Public Health Nutr. 2012;15(01):142-148.

26. Ben-Davies ME, Kinlaw A, Estrada del Campo Y, Bentley ME, Siega-Riz AM. Risk factors associated with the presence and severity of food insecurity in rural Honduras. Public Health Nutr. 2014;17(01):5-13.

27. Chambers R, von Medeazza G. Reframing Undernutrition: Faecally-Transmitted Infections and the 5 As. Brighton, UK: Institute of Development Studies; 2014.

28. Duedu KO, Peprah E, Anim-Baidoo I, Ayeh-Kumi PF. Prevalence of intestinal parasites and association with malnutrition at a Ghanaian orphanage. Hum Parasit Dis. 2015;15(7):5-9.
29. Mujica-Coopman MF, Brito A, Lopez de Romana D, Rios-Castillo I, Coris H, Olivares M. Prevalence of anemia in Latin America and the Caribbean. Food Nutr Bull. 2015;36(2 suppl):S119-S128.

30. Kim DA, Hwong AR, Stafford D, et al. Social network targeting to maximise population behaviour change: a cluster randomised controlled trial. Lancet. 2015; 386(9989):145-153.

31. Knopp S, Mohammed KA, Stothard JR, et al. Patterns and risk factors of helminthiasis and anemia in a rural and a peri-urban community in Zanzibar, in the context of helminth control programs. PLoS Negl Trop Dis. 2010;4(5):e681.

32. Yasutake S, He H, Decker MR, Sonenstein FL, Astone NM. Anemia among adolescent and young women in low-and-middle-income countries. Int J Child Health Nutr. 2013;2(2):105-112.

33. Gutierrez-Jimenez J, Torres-Sanchez MG, Fajardo-Martinez LP, et al. Malnutrition and the presence of intestinal parasites in children from the poorest municipalities of Mexico. J Infect Dev Ctries. 2013;7(10):741-747.

34. Taylor-Robinson DC, Maayan N, Soares-Weiser K, Donegan S, Garner P. Deworming drugs for soil-transmitted intestinal worms in children: effects on nutritional indicators, haemoglobin, and school performance. Cochrane Database Syst Rev. 2015;7:CD000371.

35. Hürlimann E, Houngbedji CA, Prisca B, et al. Effect of deworming on schoolaged children's physical fitness, cognition and clinical parameters in a malariahelminth co-endemic area of Cote d'Ivoire. BMC Infect Dis. 2014;14(1):411.

36. Cairncross S, Blumenthal U, Kolsky P, Moraes L, Tayeh A. The public and domestic domains in the transmission of disease. Trop Med Int Health. 1996;1(1): 27-34.

37. Olsen A, Samuelsen H, Onyango-Ouma W. A study of risk factors for intestinal helminth infections using epidemiological and anthropological approaches. J Biosoc Sci. 2001;33(4):569-584.

38. Truscott JE, Hollingsworth TD, Brooker SJ, Anderson RM. Can chemotherapy alone eliminate the transmission of soil transmitted helminths. Parasit Vectors. 2014;7(1):266.

39. Alkire S, Santos ME. Measuring acute poverty in the developing world: robustness and scope of the multidimensional poverty index. World Dev. 2014;59: 251-274.

40. Feres JC, Mancero X. [The Unsatisfied Basic Needs (UBN) Method and Its Applications in Latin America]. Santiago: CEPAL United Nations; 2001. 